CONGENITAL BLENNORRHCEA OF THE LACRYMAL SAC.

By S. G. Corner, M.A., M.B., CH.B. Edin., TATE ASSISTANT HOUSE SURGEON TO THE EVELINA HOSPIMAL FOR SICK CHILDRFY, SOUTHWARK BRIDGE ROAD, LONDON, S.E.

A CASE of this somewhat rare condition, about which the text-books say so little, seems worthy of record. It occurred in a female child at whose birth $\mathrm{I}$ was present in November, 1909. The appearance the child presented immediately after birth was as if the bridge of the nose was sunken. On closer examination, however, it was seen that this was really due to swelling of both lacrymal sacs. On the second day the swellings increased. On the third day the sacs were considerably distended, the skin over them being of purplish hue. There was a discharge of muco-purulent material through the canaliculi into the ezes, but more so in the case of the left eye, where the swelling of the tear sac was more prominent. Pressure over the distended tear sacs produced increased regurgitation of muco-pus into the eyes. On the fifth day the left eye was constantly bathed in discharge, in spite of the fact that the nurse kept washing it away with boric lotion.

Fearing that the conjunctiva would suffer if matters were left alone, I decided to incise the sac of the left side. After spraying on ethyl chloride an incision was made over the most prominent part of the swelling and an ordinary probe was passed in, but not passed down the nasal duct. The discharge into the eye immediately ceased, and in two days, with the help of boric fomentations, the swelling had entirely subsided. As there was but little discharge into the right eye the nurse was directed to press the tumour on that side downwards in the direction of the nasal duct. This treatment was effective, for in three days the bulging of the right tear sac had disappeared.

This child is the second one the mother has given birth to ; the eyes of the first-born, also a girl, had shown no abnormality at birth.

In a recent article on congenital blennorrhoea of the lacrymal sac Mr. J. R. Foster of Hartlepool states that he considers the condition to be due to obstruction of the nasal duct, "most probably where it opens into the inferior meatus of the nose." Writing about inflammation of the tear sac, Berry says that "as the mucous membrane of the sac swells its lower orifice or passage into the tear duct becomes narrowed or closed, partly by the approximation of the swollen folds of the membrane which are met with in this situation, and partly, no doubt, by the increased mucoid secretion from the swollen surface." Evidently Berry con siders that the duct may be blocked by accumulation in the sac itself, which is the dilated upper end of the duct.

In the case above recorded there was evidently no stricture of the nasal duct at its lower end, because, in the case of the left eye, the condition was relieved at once by the incision into the sac and relief of tension, and in the case of the right sac pressure downwards in the direction of the nasal duct sufficed to empty the sac by expressing the contents into the nasal duct.

Coggeshall, Fissex.

A NOTE ON A CASE OF MONGOLIAN IMBECILITY. By J. P. Cullen, M.B. Lond., M.R.C.S. ENG., D.P.H.

THE following notes on a case of Mongolian imbecility recently under my observation may be of interest as exemplifying certain factors in the etiology of this affection. The patient was a boy, aged 8 years. The family history was significant. The mother, aged 43 years, had been married for 20 years, and during that time had had seven children, two dying in early infancy, five being alive at the date of examination. In addition she had had four miscarriages, two of these between the third and fourth children, one between the fifth and sixth, and one prior to the birth of the patient, who was the seventh and last child of the series. No specific history was elicited from the mother, and no signs of congenital disease were observed on other members of the family. A history of alcohol was obtained from both the father and the mother.

The patient himself was a typical Mongol, showing a brachycephalic head with antero-posterior and transverse diameters both $12 \cdot 5$ inches, obliquely set eyes, depressed bridge of nose, furrowed tongue, and curvature of the littlefingers of both hands. He was backward at school and could. not learn, but exhibited none of the dull apathy of a cretin, his facial aspect being more alert.

The case lends support to the theory that such imbeciles are exhaustion products depending mainly on advanced maternal age and frequent child-bearing, but also due to other toxic influences of which alcohol may be one.

Plymouth.

\section{attediral Soxtectirs.}

\section{ROYAL SOCIETY OF MEDICINE.}

\section{OBSTETRICAL AND GYNACOLOGICAL SECTION.}

Abdominal Hysterectomy. - Cyst of the Broad Ligament.

A MeEting of this section was held on Dec. 9th, 1909, Dr.

H. Macnaughton-Jones, the President, being in the chair.

Dr. Philip D. TuRner (Ryde) read a paper on Abdominal Hysterectomy 63 hours After Labour for a Necrosed and Suppurating Subperitoneal Fibroid. The patient was a nullipara, aged 32 years, and had been married 13 months. She consulted Dr. Turner on March 22nd, 1909, on account of a hard lump which she had noticed in the left side of her abdomen for about a fortnight. Her last menstrual period ended on Jan. 18th. A firm, elongated, freely moveable tumour was found lying on the left side of, and attached to, the uterus, which was about two months pregnant. He considered it to be a pedunculated fibroid, and took her into hospital with the intention of removing it. On April 8th he opened the abdomen, and found that the fibroid was. attached to the uterus by a very broad base and could not be removed without terminating the pregnancy. He therefore decided to let the case go on to term and perform a myomectomy afterwards. Labour commenced on Oct. $26 \mathrm{th}$, but full dilatation was only reached on the 29th. The second stage was short and, towards the end, precipitate. The child, a boy, was born with a very long cord three times round its neck. There was rather sharp post-partum bæmorrhage, and the placenta and membranes had to ke stripped off. In doing this a very small intramural fibroid was felt in the anterior wall and a somewhat larger submucous one near the right cornu. On the morning of Nov. 1st (the third day) the patient was looking ill and anxious. The whole abdomen was somewhat tender, the temperature was $100 \cdot 2^{\circ} \mathrm{F}$, , and the pulse-rate was 126. From the steady and progressive rise in the pulse-rate, combined with the increasing pain and tenderness over the tumour, it was concluded that the fibroid was sloughing, and immediate operation was advised. The uterus was accordingly removed by Doyen's method 63 hours after the birth of the child, three or four pints of saline solution being introduced into the abdomen while the wound was being closed. This caused the pulse, which had become imperceptible, to revive. The operation lasted nearly threequarters of an hour. An hour later three pints of saline solution were introduced into the median basilic vein, with one drachm of adrenalin-1 in 1000-to each pint. The convalescence was without incident. The pulse-rate for five days did not fall below 120 and was at times as frequent as 140. The uterus contained a tumour which was of about the size of the head of a three months foetus, was slightly ovoid in shape, and had grown from the left angle of the uterus in front of the broad ligament. On incising the tumour there was a gush of excessively foul and stinking pus. The tumour was almost entirely converted into an irregular cavity lined and trabeculated by yellowish grey opaque slough. This was bounded by a layer of apparently normal fibroid tissue, which on the side nearest to the uterus was three-quarters of an inch thick, while at one point of the incision it was less than one-tenth of an inch, so that the slough was covered by very little more than the peritoneum. The necrotic change must have gone on for a considerable time before labour, but, on the other hand, the fibroid was in a normal condition when the abdomen was opened in the third month of pregnancy. The patient began 